Room for a view

\title{
White veils in her hair
}

She entered the examining room, carSrying an air of repressed urgency and quiescent anticipation. This mood, this suppression, is unusual for her, he thought. She wore white polyester, a short-sleeved shirt and long pants, and a long white apron, smeared with the day's food preparation (ketchup, butter, potato peelings) and tied with strings wrapped twice around her waist and knotted neatly at the side. Her chestnut hair was coiled into a bun, imprisoned by a white net, escaped tendrils caressing the nape of her neck, and she carried a kitchen aroma, like a freshly opened bag of potato chips, cloying.

"Doctor, please will you fill this form in for me?" A plaintive but quizzical voice, years of knowing each other adding layers to her request. "I need to get out of this place and not come back." She handed him the form, a three-paged one, and his heart fell (for he detested filling in forms) as he mused to himself, Was this why I went to medical school for 4 years?

She saw the shadow fall on his face and his jaw tighten, and she thought, He does not want to fill in this form; he thinks I am unworthy. She walked over to the edge of the window, beside his desk, to the patient's chair with its upholstered seat (chosen by an administrator, its blue linen fabric stained with indelible years of human secretions pus and blood and sweat and urine and tears and coffee and vomit) and sat down; in this definitive act of sitting she tried to control her impulse to cajole and to persuade; she crossed her hands in her lap, submitting; her knee fidgeted up and down as she waited for him to read the form. At last, she burst into the silence.

"I've never been to treatment, you know; I think it would be good for me, to do some group work, and stuff."

He smiled, the weary lines at the corners of his eyes lifting, and picked up his pen. He thought of the times she had been disruptive, an impetuous Labrador puppy, an enraged bull (he was never sure which it would be) and tried to imagine her in group therapy in a treatment centre. How will she fit in? he wondered to himself, but out loud he asked the questions written on the form: "What drugs do you use? When was the last time you used?"

She answered him and then veered sideways: "Each time when I get out of here, and I relapse, the anger just blows up; it gets so big, I can't control it; I hate what I do to others; I hate myself when this happens." She looked down at her hands. The fingers of her right hand traced red angry lines on the inside of her left arm, gouges traversing her wrist, one end oozing. "I feel so badly; I think there must be something wrong with my brain. Why do I do these things?" She leant forward now, on bent elbows at the corner of his desk, and looked up at him, her grey eyes deep shimmering pools in the institutional pallor of her face.

He looked away from her, away from those eyes and their questions; he looked down at the list of questions on the treatment centre form, down at the task lying in front of him; he asked. "Any history of sexual abuse?"

She spoke softly now. "It happened, that's all. I've never dealt with it, you know. I can't face it now. One day I will."
He reached for her left wrist, his careful fingers probing her radial artery to count her pulse (the treatment centre form required that he fill in "pulse" and "blood pressure" and "evidence of infectious disease") and, in that moment of holding her gouged left wrist in his hand, he saw her back-lit by the sunlight filtering through the window, and he saw an angel: her white gown, her white face, with shimmering pools in her eyes and white veils in her hair; he found himself lost in depths that were her eyes. He saw surf washed up by tumultuous crests, mists swathing forgotten moors, clouds unfurling in forever skies, heather tossed by winds on distant mountains, and what else he knew not; he hung there suspended, a falcon pinioned motionless by wind eddies, soaring, outside of himself, as he looked down on the two of them in a prison medical examining room.

He shook himself free, free of everything contained in that moment, and released her hand. She shrugged back into the chair, with all its stains, and breathed a sad short sigh. $\mathrm{He}$ stretched out over his desk and cranked the handle of the window latch, horizontal cracks splitting apart panes of glass, a window designed to let air in and no person out. He whispered to her - aloud or to himself, he was not sure - Fly, fly away, be in this place no more.

\section{Ruth Elwood Martin \\ Family Physician \\ Vancouver, BC}

